\title{
ST-segment re-elevation following primary angioplasty in acute myocardial infarction with patent infarct-related artery: impact on left ventricular function recovery and remodeling
}

\author{
Krzysztof Krawczyk, Konrad Stepien, Karol Nowak, Jadwiga Nessler, Jaroslaw Zalewski \\ Department of Coronary Artery Disease and Heart Failure, Jagiellonian University Medical College, John Paul II Hospital, Krakow, Poland
}

Adv Interv Cardiol 2019; 15, 4 (58): 412-421

DOI: https://doi.org/10.5114/aic.2019.90215

\begin{abstract}
A bstract
Introduction: Spontaneous recanalization of the infarct-related artery (IRA) in ST-segment elevation myocardial infarction (STEMI) before primary angioplasty (PCI) improves clinical outcomes.

Aim: To investigate the impact of ST-segment re-elevation (reSTE) following PCI in patent IRA on left ventricular (LV) function recovery and remodeling.

Material and methods: Of 155 STEMI patients with patent IRA, $19(12.3 \%)$ patients with TIMI-2 (T2 $\left.{ }_{\text {Res }}\right)$ and 85 (54.8\%) with TIMI-3 (T3 $3_{\text {Res }}$ ) had further STE resolution following PCI, 20 (12.9\%) with TIMI-3 did not require PCI (T3 $\left.3_{\text {noPC }}\right)$ and 31 (20.0\%) with TIMI$2 / 3$ had reSTE of $\geq 1 \mathrm{~mm}$ following PCl as compared with pre-PCI recordings (T23 ${ }_{\text {reste }}$ ). LV ejection fraction (LVEF, \%) and LV end-diastolic and end-systolic volume indexes (LVEDVI, LVESVI, $\mathrm{ml} / \mathrm{m}^{2}$ ) were measured by echocardiography 2 days and 6 months following PCI.

Results: In 6-month observation the improvement of LVEF in $T 3_{\text {Res }}$ (by $3.9 \pm 5.1 \%$ ) and in $T 3_{\text {nopCI }}$ (by $5.7 \pm 6.1 \%$ ) patients was higher as compared with T23 $3_{\text {reSTE }}\left(0.2 \pm 7.0 \%, p<0.05\right.$ versus both). LVEDVI increased in T23 ${ }_{\text {reSTE }}$ patients by $6.6 \pm 12.6 \mathrm{ml} / \mathrm{m}^{2}$, but decreased in T3 $3_{\text {Res }}$ by $3.8 \pm 9.7 \mathrm{ml} / \mathrm{m}^{2}$ and in T3 $3_{\text {nopC }}$ by $2.4 \pm 6.2 \mathrm{ml} / \mathrm{m}^{2}$ (for both $p<0.05 \mathrm{Vs}$. T2 $3_{\text {reSTE }}^{\text {resTE }}$. LVESVI increased in T23 $23_{\text {reSTE }}$ patients (by $3.8 \pm 10.8 \mathrm{ml} / \mathrm{m}^{2}$ ), did not change in T2 $2_{\text {Res }}$ (by $0.1 \pm 9.0 \mathrm{ml} / \mathrm{m}^{2}$ ), but decreased in T3 $3_{\text {Res }}$ (by $4.2 \pm 7.2 \mathrm{ml} / \mathrm{m}^{2}, p<0.05 \mathrm{vs}$. T2 $3_{\text {reste }}$ ) and in T3 $3_{\text {nopCI }}$ patients (by $4.7 \pm 7.7 \mathrm{ml} / \mathrm{m}^{2}, p<0.05$ Vs. T2 $3_{\text {reSTE }}$ ). ReSTE was an independent predictor of LVEF, LVEDVI and LVESVI Changes $(p<0.001$ for all).

Conclusions: ReSTE following PCI in a patent IRA is associated with a lack of improvement of LV contractility and subsequent LV remodeling.
\end{abstract}

Key words: acute myocardial infarction, primary percutaneous coronary intervention, ST-segment elevation.

Su m m a ry

The current study constitutes one of the infrequent reports regarding the clinical relevance of ST-segment re-elevation (reSTE) following primary percutaneous coronary intervention (PCI) in patients with a spontaneously recanalized infarct-related artery (IRA). We found that reSTE was independently associated with both lack of improvement of global and infarctrelated contractility as well as increase of left ventricular (LV) volumes in 6-month observation. Moreover, the procedure accompanied by reSTE was related to worse LV function and structure recovery as compared with patients with subsequent ST-segment resolution following PCI. Our findings provide evidence that myocardial injury reflected by reSTE is associated with the loss of beneficial effects of spontaneous IRA reperfusion on subsequent LV remodeling. Further studies on therapies to prevent reSTE following primary $\mathrm{PCI}$ are necessary.

\section{Introduction}

Spontaneous reperfusion characterized by a patent epicardial infarct-related artery (IRA) on initial angiogra- phy improves the prognosis in patients with myocardial infarction (MI). This phenomenon affects up to $30 \%$ of patients with ST-segment elevation myocardial infarction (STEMI) [1]. Based on the results of recent EUROMAX

\section{Corresponding author:}

Krzysztof Krawczyk MD, Department of Coronary Artery Disease and Heart Failure, Jagiellonian University Medical College, John Paul II Hospital, 80 Pradnicka St, 31-202 Krakow, Poland, e-mail: krzysztof15.krawczyk@gmail.com

Received: 9.03.2019, accepted: 5.05.2019. 
[2] and HORIZONS-AMI [3] trials, baseline thrombolysis in myocardial infarction (TIMI) 2 or 3 flow derived from spontaneous reperfusion was associated in contemporary practice with a higher rate of final TIMI 3 flow grade, decreased frequency of adverse cardiovascular events and reduced short- and long-term mortality. Similar beneficial effects were found with pharmacological reperfusion prior to percutaneous coronary intervention (PCI) [4]. According to the current guidelines [5] in patients with spontaneously normalized ST-segment elevation, angiography within $24 \mathrm{~h}$ is recommended. Moreover, recent studies showed that deferred $\mathrm{PCl}$ in spontaneously reperfused STEMI patients was associated with similar infarct size [6] and clinical outcomes $[1,6]$ as compared with immediate $\mathrm{PCl}$.

The fourth universal definition of $\mathrm{Ml}$ focused on the issue of myocardial damage associated with revascularization procedures. The procedure-related myocardial injury and $\mathrm{MI}$ associated with $\mathrm{PCl}$ (type 4a MI) were separated depending on the level of high-sensitivity cardiac troponin and the presence of new ischemic changes in ECG, cardiac imaging or angiographic findings of flow-limiting complications of $\mathrm{PCl}$ [7]. Previous studies reported that the incidence of peri-procedural MI varies from 5 to $30 \%$ and is associated with an increased risk of death (adjusted hazard ratio $(\mathrm{HR})=1.20,95 \% \mathrm{Cl}$ : 1.04-1.39) [8]. When $\mathrm{PCl}$ is performed in a prothrombotic milieu in MI patients, it is extremely difficult to estimate the magnitude of myocardial injury associated with the procedure, while the extent of infarct-related necrosis is many times greater.

It was found that ST-segment re-elevation (reSTE) following primary $\mathrm{PCl}$ observed in one fifth of patients with anterior STEMI with an occluded IRA on initial contrast injection was not associated with increased infarct size, left ventricular (LV) function or clinical outcomes at 1 year $[9,10]$. In contrast, lack of ST-segment resolution or reSTE within $24 \mathrm{~h}$ following $\mathrm{PCl}$ was associated with increased enzymatic injury and reduced LV function [11]. Moreover, in STEMI patients, microvascular obstruction and intramyocardial hemorrhage were more frequently observed in contrast-enhanced cardiac magnetic resonance of patients with reSTE during primary PCI [12]. Previous results also suggested that myocardial expansion of the infarcted portion [13] and pericarditis following MI may contribute to reSTE, but most of the available studies concerned patients with an occluded IRA.

\section{Aim}

We hypothesized that reSTE following primary $\mathrm{PCl}$ in a patent IRA might be associated with the loss of beneficial effects of spontaneous reperfusion. We sought to investigate the significance of reSTE during PCI in STEMI patients with a spontaneously recanalized IRA on LV function recovery and remodeling.

\section{Material and methods}

Of 969 consecutive STEMI patients we studied 155 (16\%) patients with a patent IRA treated in one center with primary $\mathrm{PCl}$. The inclusion criteria were chest pain onset within $12 \mathrm{~h}$ with concomitant ST-segment elevation of $\geq 1 \mathrm{~mm}$ in at least 2 contiguous leads or $\geq 2 \mathrm{~mm}$ in at least 2 contiguous precordial leads in qualifying ECG done during the first medical contact as well as initial TIMI 2 or 3 flow in the IRA on initial contrast injection during angiography. The exclusion criteria were cardiogenic shock on admission, previous coronary artery bypass surgery, history of malignancy, venous thromboembolism, liver injury (alanine aminotransferase > 1.5 ULN), serum creatinine $>177 \mu \mathrm{mol} / \mathrm{l}$ and current oral anticoagulation.

At first medical contact all patients received $300 \mathrm{mg}$ of aspirin; $114(73.5 \%)$ of them were loaded with $600 \mathrm{mg}$ of clopidogrel and $88(56.8 \%)$ received an intravenous bolus of $5000 \mathrm{IU}$ of unfractionated heparin (UFH). On admission, hemoglobin, red blood cell count, white blood cell count, platelet count, glucose, creatinine, and high-sensitivity C-reactive protein were determined by routine laboratory techniques. Immediately before $\mathrm{PCl}$, patients received a weight-adjusted bolus of UFH to achieve activated clotting time of 200-250 s. During primary PCl, 12 patients received abciximab as a bailout procedure. The Export Aspiration Catheter (Medtronic Inc., Minneapolis, Minnesota, USA) was used in 35 (22.6\%) patients.

The study protocol complying with the Declaration of Helsinki was approved by the Ethics Committee of the Jagiellonian University. All subjects gave informed consent for their participation in the study.

\section{ECG}

Standard 12-lead ECGs $(25 \mathrm{~mm} / \mathrm{s})$ obtained at the first medical contact (qualifying ECG $(\mathrm{Q})$ ), before $\mathrm{PCI}(\mathrm{B})$ and immediately after the procedure (A) were analyzed. The sum of ST-segment elevations in all leads ( $\Sigma$ ST) was measured at the J point by a single investigator blinded to the clinical and angiographic findings. If the sum of STE following PCl was higher by at least $1 \mathrm{~mm}$ as compared with pre- $\mathrm{PCl}$ recordings, this patient was classified as re-elevated. Resolution of ST-segment elevation between qualifying ECG and ECG performed before $\left(\mathrm{STR}_{\mathrm{B}}\right)$ and after (STR $)$ primary PCl was calculated according to the formulas: $\mathrm{STR}_{\mathrm{B}}=100 \%^{*}\left(\Sigma \mathrm{ST}_{\mathrm{Q}}-\Sigma \mathrm{ST}_{\mathrm{B}}\right) / \Sigma \mathrm{ST}_{\mathrm{Q}}$ and $\mathrm{STR}_{\mathrm{A}}$ $=100 \% \times\left(\Sigma S T_{Q}-\Sigma S T_{A}\right) / \Sigma S T_{Q}$.

\section{Angiography analysis}

Angiogram analysis was performed off-line for the determination of the IRA, epicardial blood flow, thrombus burden and distal embolization, based on visual inspection. Epicardial blood flow was evaluated by means of the TIMI flow scale [14], myocardial perfusion was scored according to the TIMI myocardial perfusion 
grades (TMPG) [15] and thrombus burden was assessed according to the TIMI thrombus grades [16], all before and after primary $\mathrm{PCl}$.

In addition, angiograms were analyzed for the presence of collateral flow to the IRA or the presence of flow-limiting lesions in non-IRA arteries. A detailed evaluation was performed in two contralateral projections. Two experienced investigators reviewed each coronary angiogram in a blinded fashion. In case of a lack of agreement between the two investigators, a third one was sought, and a conclusion was made.

\section{Assessment of cardiac function}

Two-dimensional transthoracic echocardiography (TTE) was performed twice, 2 days (2D) and 6 months (6M) after primary $\mathrm{PCl}$, at rest in a left decubitus position, using a Vivid S5 ultrasound machine (GE, Solingen, Germany) equipped with the multi-frequency harmonic transducer 3Sc-RS (1.3-4 MHz). All measurements were carried out according to joint recommendations of the American Society of Echocardiography and European Association of Echocardiography [17] by one observer blinded to clinical and angiographic data. Images were recorded in the parasternal long axis, parasternal short axis, apical four-chamber, apical two-chamber, and apical long axis views of the LV. In apical four-chamber and apical two-chamber views, LV end-diastolic (LVEDV) and end-systolic (LVESV) volumes and ejection fraction (LVEF) were calculated according to the biplane Simpson method. The values of LVEDV and LVESV were subsequently indexed to the body surface area (LVEDVI, LVESVI [ml/ $\left.\mathrm{m}^{2}\right]$ ). The wall motion score index was calculated for IRA territory (IRA-WMSI) [18]. Based on the current recommendations [17], a 16-segment model for LV segmentation and classification of territories supplied by each coronary artery were used. Wall motion of each segment was analyzed individually by a trained physician and scored as normal or hyperkinetic -1 , hypokinetic -2 , akinetic -3 and dyskinetic (or aneurysmatic) - 4. The function of each segment was validated in multiple views and the IRA-WMSI was expressed as the average value from all analyzed segments in the IRA territory.

\section{Clinical outcomes}

A 1-year clinical outcome included death, recurrent $\mathrm{MI}$, and recurrent hospitalization due to symptoms of heart failure. Event-free survival after 1-year observation was defined as freedom from death, reinfarction, and repeated cardiovascular hospitalization.

Data were obtained from the hospital records and supplemented by direct and/or telephone interview with the patient. Cardiac function at the end of the study was assessed according to the New York Heart Association functional scale (NYHA). The NYHA functional class was determined by direct contact or telephone interview with patients.

\section{Statistical analysis}

Statistical analyses were performed with Statistica 6 (StatSoft, Inc). Continuous variables are expressed as a mean \pm standard deviation or median (interquartile range) and categorical variables as a number (percentage). Continuous variables were first checked for normal distribution by the Shapiro-Wilk statistic and compared by ANOVA when normally distributed or by the KruskalWallis test for non-normally distributed variables, both with appropriate post-hoc tests. Categorical variables were analyzed by $\chi^{2}$ or Fisher's exact test. Pearson's or Spearman's rank correlation coefficients were calculated to test the association between two variables with a normal or non-normal distribution, respectively. Multivariate regression analysis was used to determine independent predictors of changes of LV function and remodeling. A $p$-value of less than 0.05 was considered statistically significant.

\section{Results}

Of 155 STEMI patients with a patent IRA at baseline, 19 (12.3\%) patients with TIMI-2 flow (T2 $\left.{ }_{\text {Res }}\right)$ and 85 (54.8\%) patients with TIMI-3 flow (T3 ${ }_{\text {Res }}$ ) achieved further STE resolution following $\mathrm{PCl}, 31$ (20.0\%) patients with TIMI-2 $(n=5)$ or $3(n=26)$ flow developed reSTE of $\geq 1 \mathrm{~mm}$ following $\mathrm{PCl}$ as compared with pre-PCI recordings (T23 $\left.3_{\text {reste }}\right)$ and the last 20 (12.9\%) patients with baseline TIMI-3 did not require $\mathrm{PCI}$ because of residual stenosis of less than $50 \%\left(\mathrm{~T}_{\text {nopCl }}\right)$.

Patients' baseline and procedural characteristics are shown in Tables I and II. The studied groups did not differ in terms of demographic variables, cardiovascular risk factors, time of ischemia, laboratory results, IRA distribution or prehospital pharmacological regimen (Table I). Among the compared groups, there were also no significant differences in the thrombus burden expressed as TIMI thrombus grade (TTG) or distal embolization; however, incomplete TMGP-0/1 perfusion was more frequently observed in $\mathrm{T} 2_{\text {Res }}$ patients before $\mathrm{PCl}$ and in $\mathrm{T} 2_{\text {Res }}$ and $\mathrm{T} 23_{\text {reSTE }}$ patients after $\mathrm{PCl}$ as compared with remaining subgroups; therefore these patients required abciximab use the most frequently (Table II).

\section{Changes of ST-segment elevation}

Among the compared groups, there was no significant difference in the sum of STE in qualifying ECG $(p=0.10)$; however, there were significant differences of STE in ECGs recorded before $(p=0.005)$ and after PCI $(p<0.001)$ (Figure $1 \mathrm{~A})$. Before $\mathrm{PCl}, \mathrm{STE}$ was significantly higher in $\mathrm{T} 2_{\text {Res }}$ patients as compared with $\mathrm{T} 3_{\text {Res }}$ (mean difference: $4.0 \mathrm{~mm}, 95 \% \mathrm{Cl}: 0.7-7.3 \mathrm{~mm}$ ) and $\mathrm{T} 3_{\text {nopc }}$ 
Table I. Baseline characteristics of studied patients

\begin{tabular}{|c|c|c|c|c|c|}
\hline Parameter & $\begin{array}{l}\text { T3 } \\
n=85\end{array}$ & $\begin{array}{l}\mathrm{T}_{2} 3_{\text {reSTE }} \\
n=31\end{array}$ & $\begin{array}{l}\mathrm{T} 2_{\text {Res }} \\
n=19\end{array}$ & $\begin{array}{l}\mathrm{T} 3_{\text {noPCI }} \\
n=20\end{array}$ & $P$-value \\
\hline Age [years] & $56(49-64)$ & $57(49-66)$ & $61(50-67)$ & $59(53-69)$ & 0.55 \\
\hline Male gender & $64(75.3)$ & $26(83.9)$ & $14(73.7)$ & $14(70.0)$ & 0.62 \\
\hline \multicolumn{6}{|l|}{ Cardiovascular risk factors: } \\
\hline Hypertension & $52(61.2)$ & $15(48.4)$ & $14(73.7)$ & $11(55.0)$ & 0.33 \\
\hline Diabetes mellitus & $18(21.2)$ & $7(22.6)$ & $6(31.6)$ & $4(20.0)$ & 0.99 \\
\hline Dyslipidemia & $47(55.3)$ & $16(51.6)$ & $12(63.2)$ & $12(60.0)$ & 0.78 \\
\hline Smoking & $55(64.7)$ & $19(61.3)$ & $13(68.4)$ & $14(70.0)$ & 0.81 \\
\hline $\begin{array}{l}\text { Family history of coronary } \\
\text { artery disease }\end{array}$ & $18(21.1)$ & $6(19.4)$ & $4(21.1)$ & $5(25.0)$ & 0.91 \\
\hline Prior stroke & $1(1.2)$ & $1(3.2)$ & 0 & $1(5.0)$ & 0.59 \\
\hline Peripheral artery disease & $4(4.7)$ & $2(6.5)$ & $1(5.3)$ & $1(5.0)$ & 0.98 \\
\hline Renal failure & $3(3.5)$ & $1(3.2)$ & 0 & 0 & 0.71 \\
\hline Previous MI & $7(11.8)$ & $3(9.7)$ & $2(10.5)$ & $1(5.0)$ & 0.92 \\
\hline Prior PCl & $5(5.9)$ & $2(6.5)$ & 0 & 0 & 0.49 \\
\hline Killip class on admission: & & & & & 0.27 \\
\hline 1 & $79(92.9)$ & $27(87.0)$ & $14(73.7)$ & $18(90.0)$ & \\
\hline 2 & $4(4.7)$ & $2(6.5)$ & $3(15.8)$ & $2(10.0)$ & \\
\hline 3 & $2(2.4)$ & $2(6.5)$ & $2(10.5)$ & 0 & \\
\hline Chest pain on admission & $9(10.6)$ & $5(16.1)$ & $5(26.3)$ & $2(10.0)$ & 0.30 \\
\hline $\begin{array}{l}\text { Onset of chest pain to balloon } \\
\text { inflation, min }\end{array}$ & $270(212-382)$ & $255(210-285)$ & $225(170-280)$ & $242(201-333)$ & 0.11 \\
\hline $\begin{array}{l}\text { Loading dose of clopidogrel to } \\
\text { admission, min }\end{array}$ & $70(50-108)$ & $71(51-110)$ & $62(45-101)$ & $67(50-105)$ & 0.42 \\
\hline White blood cells $\left[\times 10^{3} / \mu l\right]$ & $10.7(9.0-13.7)$ & $11.2(9.2-13.8)$ & $10.9(9.0-13.6)$ & $11.2(9.2-13.8)$ & 0.35 \\
\hline Hemoglobin [g/dl] & $14.5(13.4-15.2)$ & $14.2(13.0-14.5)$ & $14.3(13.2-14.7)$ & $14.4(13.1-14.8)$ & 0.42 \\
\hline Platelet count $\left[\times 10^{3} / \mu l\right]$ & $218(190-271)$ & $230(184-269)$ & $222(178-255)$ & $240(193-281)$ & 0.57 \\
\hline Glucose $[\mathrm{mmol} / \mathrm{l}]$ & $8.4(7.2-10.3)$ & $7.5(6.6-9.0)$ & $7.7(6.8-9.2)$ & $7.9(7.1-9.4)$ & 0.23 \\
\hline Creatinine $[\mu \mathrm{mol} / \mathrm{l}]$ & $94(78-105)$ & $88(77-103)$ & $92(79-105)$ & $95(80-107)$ & 0.41 \\
\hline hs C-reactive protein [mg/l] & $1.9(1.0-6.2)$ & $2.9(1.7-28.6)$ & $2.3(1.2-8.4)$ & $4.1(2.7-32.6)$ & 0.16 \\
\hline Hospitalization [days] & $5(3-6)$ & $4(3-6)$ & $4(3-6)$ & $4(3-6.75)$ & 0.76 \\
\hline \multicolumn{6}{|l|}{ 12-month follow-up: } \\
\hline Death & 0 & 0 & 0 & 0 & NA \\
\hline Recurrent MI & $2(2.4)$ & 0 & 0 & 0 & 0.68 \\
\hline $\begin{array}{l}\text { Symptoms of heart failure } \\
(\mathrm{NYHA} \geq 2)\end{array}$ & $10(11.8)$ & $7(22.6)$ & $3(15.8)$ & $1(5.0)$ & 0.29 \\
\hline $\begin{array}{l}\text { Recurrent hospitalization } \\
\text { due to heart failure }\end{array}$ & $4(4.7)$ & $2(6.5)$ & $2(10.5)$ & $1(5.0)$ & 0.80 \\
\hline
\end{tabular}

Data are expressed as number (percentage) or median (interquartile range). MI- myocardial infarction, NYHA - New York Heart Association, PCI - percutaneous coronary intervention, $T 2_{\text {Res }}-$ TIMI-2 flow with ST-segment resolution following PCI, T23 ${ }_{\text {reSTE }}-T I M I-2 / 3$ flow with ST-segment re-elevation following PCI, T3 ${ }_{\text {noPCI }}-T I M I-3$ flow without $P C I, T 3_{\text {Res }}-T I M I-3$ flow with ST-segment resolution following $P C I$.

(5.0 mm, 95\% Cl: 0.8-0.1 mm). After PCl, residual STE was significantly higher in $\mathrm{T} 23_{\text {reSTE }}$ as compared with $\mathrm{T} 3_{\text {Res }}$ $(5.0 \mathrm{~mm}, 95 \% \mathrm{Cl}: 3.4-6.8 \mathrm{~mm})$ and $\mathrm{T} 2_{\text {Res }}(2.3 \mathrm{~mm}, 95 \% \mathrm{Cl}$ : 0.5-5.2 mm). There were also significant differences of $\operatorname{STR}_{\mathrm{B}}(p=0.008)$ and $\operatorname{STR}_{\mathrm{A}}(p<0.001)$ (Figure $\left.1 \mathrm{~B}\right)$.
$\mathrm{STR}_{\mathrm{B}}$ was significantly lower in $\mathrm{T} 2_{\text {Res }}$ patients as compared with $\mathrm{T}_{\text {noPl }}(36.8 \%, 95 \% \mathrm{Cl}: 8.2-65.4 \%)$. STR was significantly lower in T23 resTE as compared with both $\mathrm{T}_{\text {Res }}(36.0 \%, 95 \% \mathrm{Cl}: 24.2-47.4 \%)$ and $\mathrm{T}_{\text {Res }}(22.8 \%$, 95\% Cl: 6.4-39.1\%). 
Table II. Antithrombotic pharmacotherapy and invasive procedure

\begin{tabular}{|c|c|c|c|c|c|}
\hline Parameter & $\begin{array}{c}T 3_{\text {Res }} \\
n=85\end{array}$ & $\begin{array}{l}\text { T23 }{ }_{\text {reSTE }} \\
n=31\end{array}$ & $\begin{array}{c}\mathrm{T} 2_{\text {Res }} \\
n=19\end{array}$ & $\begin{array}{l}T 3_{\text {noPCI }} \\
n=20\end{array}$ & $P$-value \\
\hline Aspirin, 300 mg p.o.: & & & & & 1.0 \\
\hline Pre-hospital FMC & $85(100)$ & $31(100)$ & $19(100)$ & $20(100)$ & \\
\hline Clopidogrel, 600 mg p.o.: & & & & & 0.65 \\
\hline Pre-hospital FMC & $65(76.5)$ & $22(71.0)$ & $13(68.4)$ & $14(70.0)$ & \\
\hline During PCl & $30(23.5)$ & $9(29.0)$ & $6(31.6)$ & $6(30.0)$ & \\
\hline Unfractionated heparin & & & & & 0.98 \\
\hline Pre-hospital FMC, $5000 \mathrm{IU}$ i.V. & $48(56.5)$ & $17(54.8)$ & $11(57.9)$ & $12(60.0)$ & \\
\hline Abciximab i.v.: & & & & & 0.002 \\
\hline During $\mathrm{PCl}$, as a bail-out procedure & $2(2.6)$ & $6(19.4)$ & $4(21.1)$ & 0 & \\
\hline Infarct-related artery: & & & & & 0.21 \\
\hline Left anterior descending & $35(41.2)$ & $18(58.0)$ & $12(63.2)$ & $10(50.0)$ & \\
\hline Left circumflex & $9(10.6)$ & $2(6.5)$ & $1(5.3)$ & $2(10.0)$ & \\
\hline Right coronary artery & $41(48.2)$ & $11(35.5)$ & $6(31.5)$ & $8(40.0)$ & \\
\hline TIMI at baseline: & & & & & NA \\
\hline 2 & 0 & $5(16.1)$ & $19(100)$ & 0 & \\
\hline 3 & $85(100)$ & $26(83.9)$ & 0 & $20(100)$ & \\
\hline TIMI after PCI: & & & & & 0.008 \\
\hline 2 & $2(2.4)$ & $4(12.9)$ & $4(21.1)$ & NA & \\
\hline 3 & $83(97.6)$ & $27(87.1)$ & $15(78.9)$ & NA & \\
\hline TMPG before PCI: & & & & & $<0.001$ \\
\hline $0 / 1$ & $3(3.5)$ & $4(12.9)$ & $8(42.1)$ & $4(20.0)$ & \\
\hline $2 / 3$ & $82(96.5)$ & $27(87.1)$ & $11(57.9)$ & $16(80.0)$ & \\
\hline TMPG after PCI: & & & & & $<0.001$ \\
\hline $0 / 1$ & $5(5.9)$ & $13(41.9)$ & $6(31.6)$ & NA & \\
\hline $2 / 3$ & $80(94.1)$ & $18(58.1)$ & $13(68.4)$ & NA & \\
\hline Distal embolization & $5(5.9)$ & $2(9.7)$ & $1(5.3)$ & 0 & 0.73 \\
\hline TIMI thrombus grade & & & & & 0.39 \\
\hline $0-2$ & $76(89.4)$ & $26(83.9)$ & $15(78.9)$ & $19(95.0)$ & \\
\hline $3-4$ & $9(10.6)$ & $5(16.1)$ & $4(21.1)$ & $1(5.0)$ & \\
\hline
\end{tabular}

Data are expressed as number (percentage). FMC - first medical contact, PCI - percutaneous coronary intervention, TIMI - thrombolysis in myocardial infarction, TMPG - TIMI myocardial perfusion grade, T2 $2_{\text {Res }}$ - TIMI-2 flow with ST-segment resolution following PCI, T23 resTE - TIMI-2/3 flow with ST-segment re-elevation following PCI, T3 ${ }_{\text {noPCI }}-$ TIMI-3 flow without PCI, T3 Res RIMI-3 flow with ST-segment resolution following PCI.

\section{Evolution of LV systolic function}

Among the compared groups, there were significant differences of $L V$ ejection fraction 2 days $(p=0.001)$ and 6 months following PCI $(p=0.005)$ (Figure 2 A). $\operatorname{LVEF}_{2 \mathrm{D}}$ was significantly lower in T23 $3_{\text {resTE }}$ patients as compared with $\mathrm{T}_{\text {Res }}$ (mean difference: $7.4 \%, 95 \% \mathrm{Cl}: 2.5-12.3 \%$ ). In 6-month observation, LVEF increase in T3 Res (by $3.9 \pm 5.1 \%$ ) and in $\mathrm{T} 3_{\text {nopCI }}$ (by $5.7 \pm 6.1 \%$ ) patients was higher as compared with that in T23 ${ }_{\text {reSTE }}$ patients $(0.2 \pm 7.0 \%, p<0.05$ for both) (Figure 2 B). At 6M, LVEF was significantly lower in

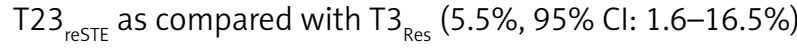

and $\mathrm{T3}_{\text {nopCl }}$ (3.3\%, 95\% Cl: 6.4-39.1\%). In $\mathrm{T}_{\text {Res }}$ patients, LVEF did not change significantly in 6-month observation.

There were also significant differences in wall motion score index values calculated for infarct-related territory (IRA-WMSI) both 2 days $(p=0.03)$ and 6 months following PCI $(p<0.001)$ (Figure 2 C). The IRA-WMSI ${ }_{2 D}$ was significantly higher in $\mathrm{T} 23_{\text {reSTE }}$ patients as compared with $\mathrm{T}_{\text {Res }}$ (mean difference: $0.25,95 \% \mathrm{Cl}$ : 0.02-0.49). In 6-month observation, IRA-WMSI improvement in T3 (by $0.33 \pm 0.25$ ) and in $T 3_{\text {nopCI }}$ (by $0.24 \pm 0.29$ ) patients was higher as compared with $T 23_{\text {reSTE }}$ patients $(0.08 \pm 0.35$, 

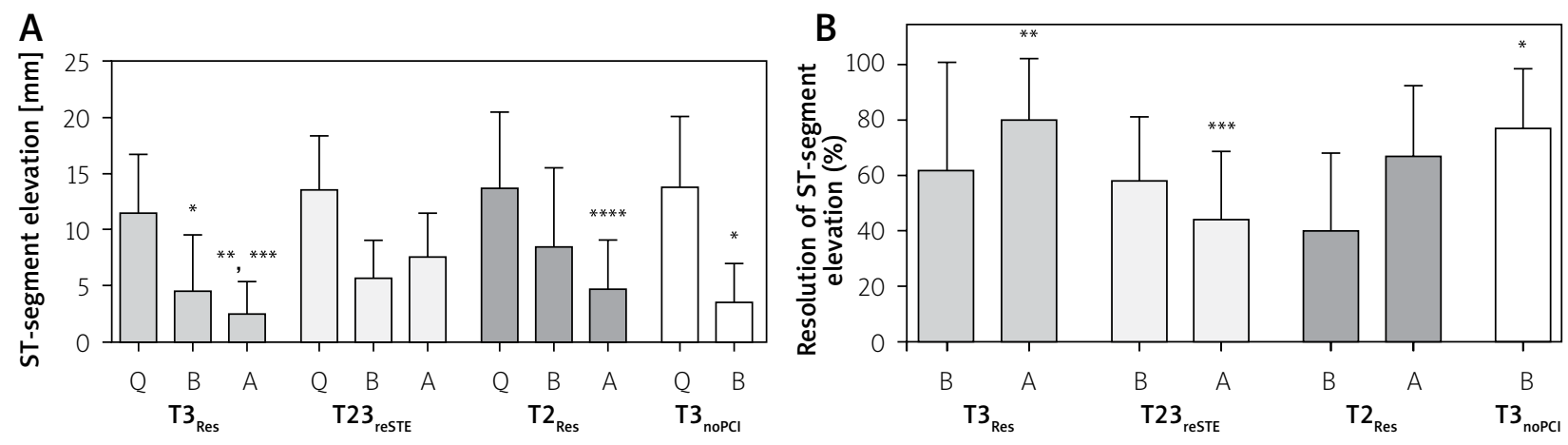

Figure 1. Changes of ST-segment elevation and ST-segment elevation resolution in the studied patients

Data are shown as mean and standard deviation. $Q, B, A-E C G$ recorded at first medical contact, before and after $P C I$, respectively. T2 $2_{\text {Res }}-T I M I-2$ flow with ST-segment resolution following PCI, T23 $3_{\text {reSTE }}$ - TIMI-2/3 flow with ST-segment re-elevation following PCI, T3 $3_{\text {noPC }}-$ TIMI-3 flow without PCI, T3 flow with ST-segment resolution following PCI. ${ }^{*} P<0.05$ vs. B-T2Res, ${ }^{* *} p<0.001$ vs. A-T23reSTE, ${ }^{* * *} p<0.05$ vs. A-T2Res, ${ }^{* * * *} p<0.05$ vs. A-T23reSTE.

A

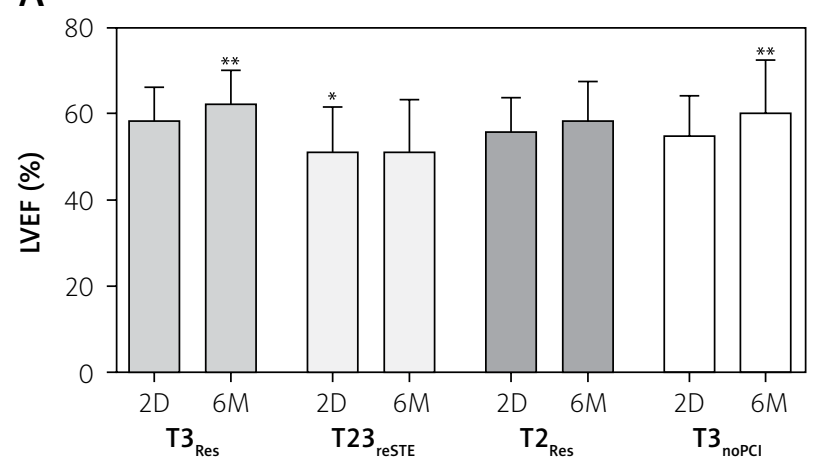

C

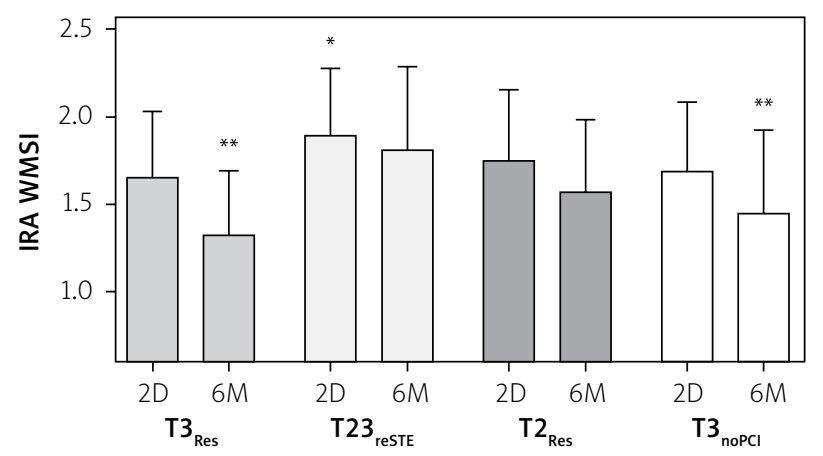

B

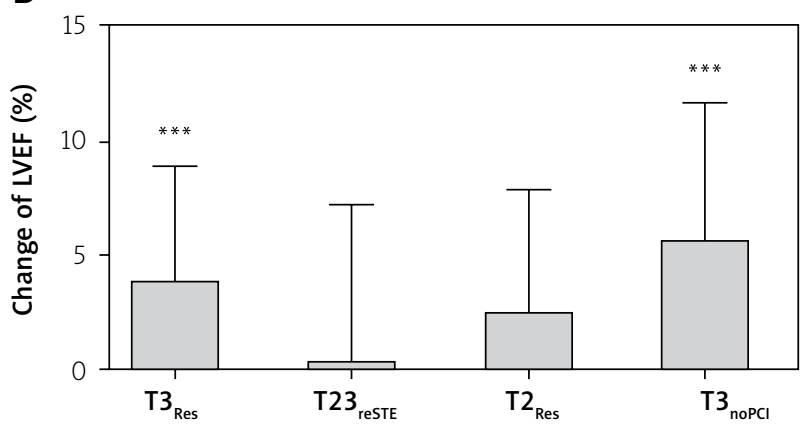

D

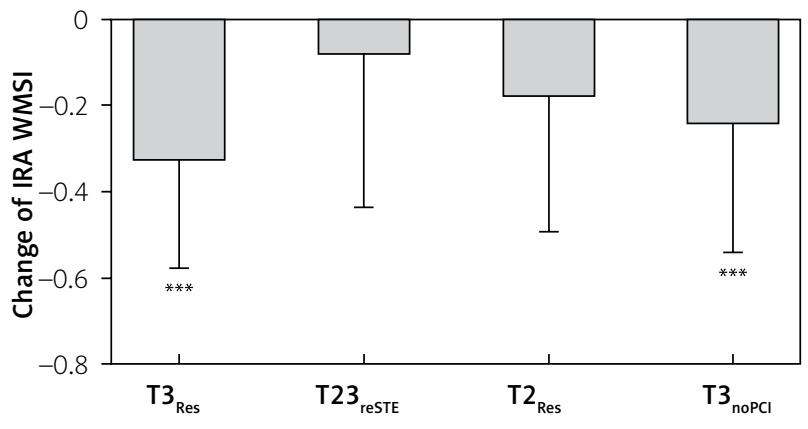

Figure 2. Changes of global and infarct-related contractility of left ventricle

Data are shown as mean and standard deviation. $2 D$ - measurements performed 2 days after $P C l, 6 M$ - measurements performed 6 months after $P C I$, LVEF - left ventricular ejection fraction, IRA WMSI - wall motion index score for infarct-related territory, T2 $2_{\text {Res }}-$ TIMI-2 flow with ST-segment resolution following PCI, T2 $3_{\text {reSTF }}$ - TIMI-2/3 flow with ST-segment re-elevation following PCI, T3 $3_{\text {noPC }}-$ TIMI-3 flow without PCI, T3 $3_{\text {Res }}-T I M I$ - 3 flow with ST-segment resolution following $P C I .{ }^{*} P<0.001$ vs. $2 D-T 3_{\text {Res, }}{ }^{* *} p<0.01$ vS. $6 M-T 23_{\text {resTe }}{ }^{* * *} p<0.05$ vs. T23 resTE

$p<0.05$ for both) (Figure $2 \mathrm{D})$. In T2 $2_{\text {Res }}$ patients, IRA-WMSI did not change in 6-month observation. At 6 months, differences in IRA-WMSI were more pronounced and IRA-WMSI was significantly higher in $\mathrm{T} 23_{\text {reste }}$ as compared with $\mathrm{T} 3_{\text {Res }}(0.49,95 \% \mathrm{Cl}: 0.25-0.72)$ and $\mathrm{T}_{\text {nopCl }}$ (0.36, 95\% Cl: 0.04-0.68).

\section{LV remodeling}

There were no differences among the compared groups in terms of baseline LVEDVI $(p=0.89)$ and LVESVI
( $p=0.08$ ) (Figures $3 \mathrm{~A}, \mathrm{C})$. In 6-month follow-up, LVEDVI increased in $T 23_{\text {reSTE }}$ by $6.6 \pm 12.6 \mathrm{ml} / \mathrm{m}^{2}$ and decreased in group T3 $3_{\text {Res }}$ by $3.8 \pm 9.7 \mathrm{ml} / \mathrm{m}^{2}$ and T3 ${ }_{\text {noPCl }}$ by $2.4 \pm 6.2 \mathrm{ml} / \mathrm{m}^{2}$ (for both $p<0.05$ vs. T23 $3_{\text {reSTE }}$ ) (Figure $3 \mathrm{~B}$ ). In T2 $2_{\text {Res }}$ patients, LVEDVI did not change significantly in 6-month observation. Therefore, after 6 months, LVEDVI was significantly higher in $\mathrm{T} 23_{\text {reSTE }}$ as compared with $\mathrm{T} 3_{\text {Res }}$ $\left(9.9 \mathrm{ml} / \mathrm{m}^{2}, 95 \% \mathrm{Cl}: 0.6-19.3 \mathrm{ml} / \mathrm{m}^{2}\right)$ (Figure $3 \mathrm{~A}$ ).

In 6-month follow-up, LVESVI increased in T23 $3_{\text {reSTE }}$ (by $3.8 \pm 10.8 \mathrm{ml} / \mathrm{m}^{2}$ ) patients, did not change significantly in 
A

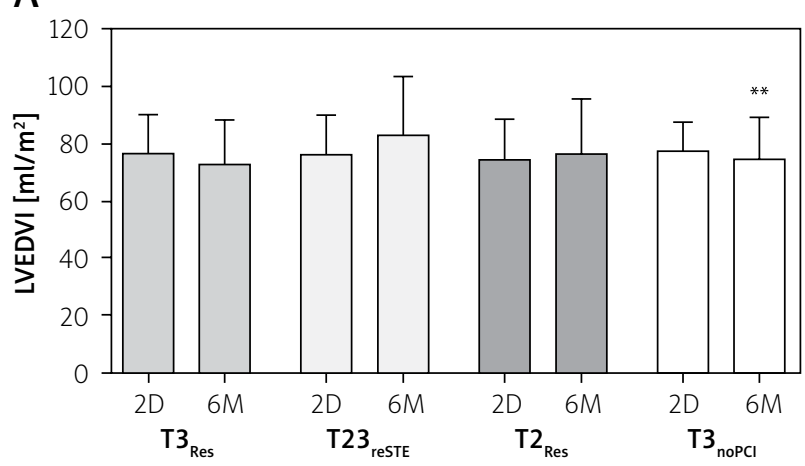

C

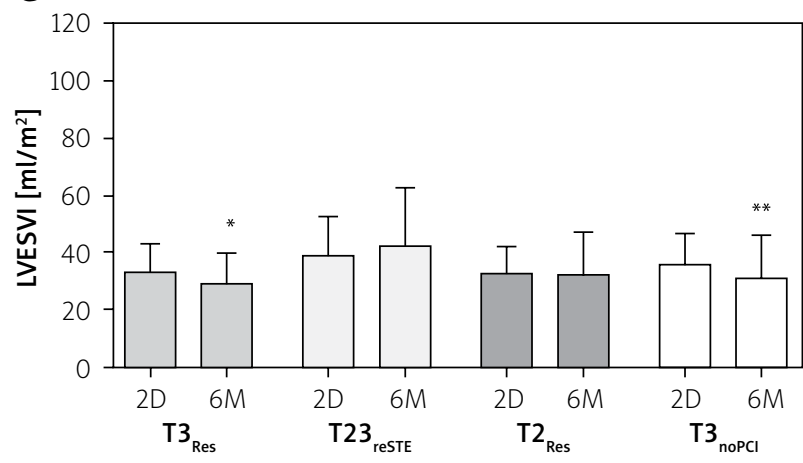

B

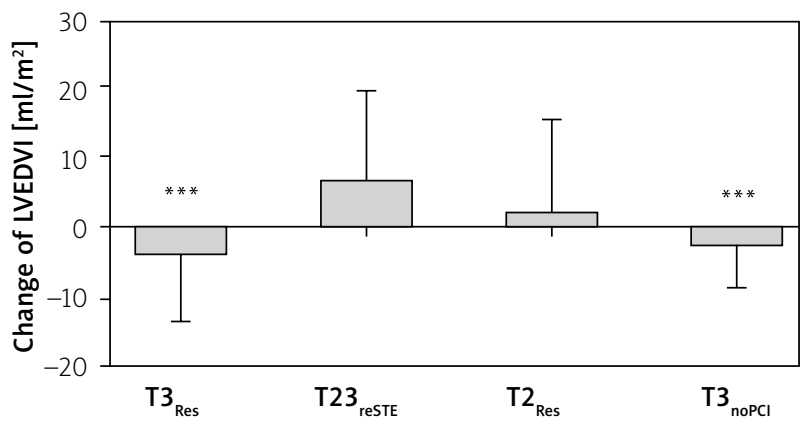

D

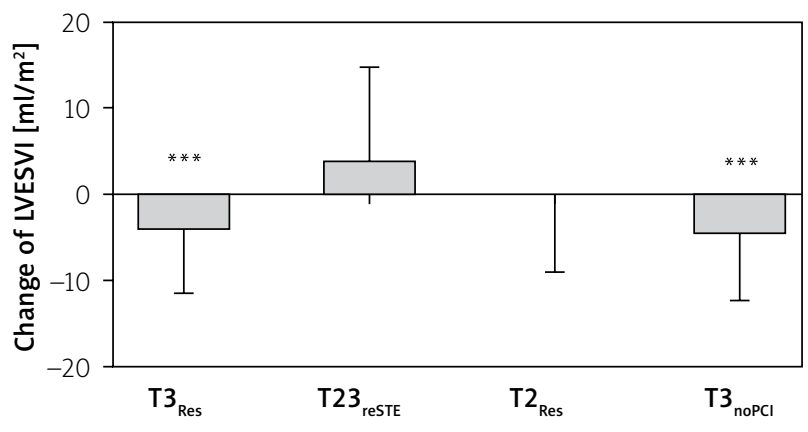

Figure 3. Changes of left ventricular volume indexes

Data are shown as mean and standard deviation. $2 D$ - measurements performed 2 days after $P C I, 6 M$ - measurements performed 6 months after $P C I$, LVEDVI - left ventricular end-diastolic volume index, LVESVI - left ventricular end-systolic volume index, T2 $2_{\text {Res }}-$ TIMI-2 flow with ST-segment resolution following PCI, T23 $3_{\text {reSTE }}-$ TIMI-2/3 flow with ST-segment re-elevation following PCI, T3 $3_{\text {noPCI }}-$ TIMI-3 flow without PCI, T3 ${ }_{\text {Res }}-T I M I-3$ flow with ST-segment resolution following $P C l .{ }^{*} P<0.001$ vs. $6 M-T 23_{\text {reSTP }}{ }^{* *} p<0.01$ vs. $6 M-T 23_{\text {reSTP }}{ }^{* * *} p<0.05$ VS. T23 ${ }_{\text {reSTE }}$

T2 (b) $0.1 \pm 9.0 \mathrm{ml} / \mathrm{m}^{2}$ ) patients, whereas it decreased in T3 ${ }_{\text {Res }}$ (by $4.2 \pm 7.2 \mathrm{ml} / \mathrm{m}^{2}$ ) and in T3 ${ }_{\text {noPCl }}$ (by $4.7 \pm 7.7 \mathrm{ml}$ / $\mathrm{m}^{2}$ ) patients (for both $p<0.05$ as compared with $T 23_{\text {reSTE }}$ ) (Figure $3 \mathrm{D}$ ). Finally, after 6 months LVESVI was significantly higher in T23 $3_{\text {reSTE }}$ as compared with $\mathrm{T} 3_{\text {Res }}\left(13.8 \mathrm{ml} / \mathrm{m}^{2}\right.$, $\left.95 \% \mathrm{Cl}: 5.8-21.9 \mathrm{ml} / \mathrm{m}^{2}\right)$ and with $\mathrm{T} 3_{\text {noPCl }}\left(11.5 \mathrm{ml} / \mathrm{m}^{2}\right.$, 95\% Cl: $0.5-22.4 \mathrm{ml} / \mathrm{m}^{2}$ ) (Figure $3 \mathrm{C}$ ).

\section{Clinical outcomes}

The time of hospitalization and the number of patients with symptoms of heart failure in the NYHA scale $\geq 2$ after 12 months were similar in all groups (Table I). In 12-month follow-up, there were no deaths, 2 (1.3\%) patients had recurrent $\mathrm{MI}$ and $9(5.8 \%)$ required hospitalization due to symptoms of heart failure. There were no significant intergroup differences (Table I).

\section{Predictive value of reSTE}

The multivariate models for the recovery of LV function and LV remodeling are shown in Table III. Independent variables identified as associated $(p<0.2)$ with dependent variables in the univariate model (Tables I, II) were included in the multivariate regression models. Moreover, significant correlations between independent variables including $\mathrm{LVEF}_{2 \mathrm{D}}$ and infarct territory $(r=0.31$, $p<0.001), \operatorname{LVEF}_{2 \mathrm{D}}$ and the incidence of reSTE $(r=0.28$, $p<0.001), \operatorname{LVEDVI}_{2 \mathrm{D}}$ and infarct territory $(r=0.19, p=0.011)$ and LVESVI ${ }_{2 D}$ and infarct territory $(r=0.40, p<0.001)$ were found. In final multivariate models, reSTE and baseline LVEF independently affected changes of LVEF with variance of $R^{2}=0.31$ ( $p=0.002$ ) (Table III), whereas only reSTE independently predicted changes of both LVEDVI and LVESVI with variance of $R^{2}=0.35$ and $R^{2}=0.36$, respectively ( $p<0.001$ for both).

\section{Discussion}

To our knowledge, the current study constitutes one of the infrequent reports regarding clinical relevance of reSTE following primary $\mathrm{PCI}$ in patients with spontaneously recanalized IRA. We demonstrated that reSTE was independently associated with both lack of improvement of global and infarct-related contractility and increase of LV volume in 6-month observation. Moreover, the procedure accompanied by reSTE was related to worse LV function and structure recovery as compared with patients with subsequent ST-segment resolution following $\mathrm{PCl}$. Our findings provide evidence that myocardial injury reflected by reSTE is associated with the loss of beneficial effects of spontaneous IRA reperfusion on further LV remodeling. 
Table III. Independent predictors of changes of LVEF, LVEDVI and LVESVI

\begin{tabular}{|c|c|c|c|c|c|c|c|}
\hline \multirow{2}{*}{$\begin{array}{l}\text { Dependent } \\
\text { variable }\end{array}$} & \multirow[t]{2}{*}{ Independent variable } & \multicolumn{3}{|c|}{ Univariate model } & \multicolumn{3}{|c|}{ Multivariate model } \\
\hline & & Coefficient B & $P$-value & $\begin{array}{c}95 \% \mathrm{Cl} \text { for } \\
\text { coefficient B }\end{array}$ & Coefficient B & $P$-value & $\begin{array}{c}95 \% \mathrm{Cl} \text { for } \\
\text { coefficient B }\end{array}$ \\
\hline \multirow{2}{*}{$\begin{array}{l}\text { Delta LVEF } \\
R^{2}=0.31 \\
p<0.001\end{array}$} & reSTE (Yes/No) & -3.73 & 0.001 & $-6.00--1.47$ & -4.35 & $<0.001$ & $-6.71--1.99$ \\
\hline & $\operatorname{LVEF}_{2 \mathrm{D}}($ per 1\%) & -0.09 & 0.17 & $-0.17-0.07$ & -0.11 & 0.047 & $-0.22--0.01$ \\
\hline \multirow{2}{*}{$\begin{array}{l}\text { Delta LVEDVI } \\
R^{2}=0.35 \\
p<0.001\end{array}$} & reSTE (Yes/No) & 9.25 & $<0.001$ & $5.06-13.44$ & 8.58 & $<0.001$ & $4.32-12.84$ \\
\hline & LAD as IRA (Yes/No) & 4.09 & 0.023 & $0.57-7.60$ & 2.70 & 0.122 & $-0.73-6.12$ \\
\hline \multirow{3}{*}{$\begin{array}{l}\text { Delta LVESVI } \\
R^{2}=0.36 \\
p<0.001\end{array}$} & reSTE (Yes/No) & 7.47 & $<0.001$ & $4.14-10.81$ & 7.08 & $<0.001$ & $3.63-10.54$ \\
\hline & LAD as IRA (Yes/No) & 2.29 & 0.112 & $-0.54-5.11$ & 0.95 & 0.514 & $-1.91-3.81$ \\
\hline & $\operatorname{LVESVI}_{2 \mathrm{D}}\left(\right.$ per $\left.1 \mathrm{ml} / \mathrm{m}^{2}\right)$ & 0.09 & 0.162 & $-0.04-0.22$ & 0.03 & 0.660 & $-0.10-0.16$ \\
\hline
\end{tabular}

IRA - infarct-related artery, LAD - left anterior descending artery, LVEF - left ventricular ejection fraction, LVEDVI - left ventricular end-diastolic volume index, $L V E S V I$ - left ventricular end-systolic volume index, reSTE - ST-segment re-elevation following $P C I, 2 D$ - measurements performed two days after $P C I$, $R^{2}-$ variance.

Our study also provides some evidence regarding the mechanism of reSTE. We have shown that angiographically visible distal embolization occurred in around 10\% of patients with reSTE and occurred in a similar proportion in the remaining analyzed groups and other studies $[19,20]$. Moreover, we found no significantly different distribution of TIMI thrombus grades in the compared groups, which suggests a lack of unquestionable association between reSTE and angiographically evident residual epicardial thrombus. Simultaneously, the results of our study emphasize the role of impaired microvascular perfusion in patients with reSTE. Incomplete TMPG-0/1 reperfusion after $\mathrm{PCl}$ was the most frequent in patients with reSTE. Moreover, in about $30 \%$ of patients with reSTE, myocardial perfusion was deteriorated from baseline TMPG-2/3 to $0 / 1$ following $P C l$. This observation is consistent with our previous findings [21] and reports on microvascular injury assessed with cardiac magnetic resonance in patients with reSTE [12]. It might be speculated that during balloon inflation, the components of ruptured plaque containing connective tissue elements and subendothelial matrix proteins are exposed to the bloodstream and initialize platelet activation, thrombin generation followed by thrombus formation and promote vasospasm. Prothrombotic material protruding through the struts during stent implantation together with the already present intraluminal thrombus may lead to epicardial blood flow deterioration [22] and microvascular plugging [23]. Identification of the key factor involved in myocardial perfusion deterioration in patients with reSTE after spontaneous reperfusion requires further studies with the use of optical coherent tomography. Interestingly, in our study reSTE was associated with a similar systemic inflammatory response as measured by white blood cell count and hsCRP level. In contrast, a previous study reported that CRP concentration in STEMI patients with reSTE was higher, reflecting more intensified reperfusion injury [11].
In our group, unfavorable echocardiographic findings related to reSTE did not affect the duration of hospitalization or 1-year clinical outcomes. Research conducted so far regarding the impact of reSTE following $\mathrm{PCI}$ on LV function concerns mainly patients with initially occluded IRA. In a small observational study including 41 STEMI patients, Weaver et al. [12] found a significant relationship between reSTE and the extent of myocardial injury assessed by contrast-enhanced cardiac magnetic resonance. In turn, Okuda et al. [11] revealed that reSTE in patients who underwent both primary $\mathrm{PCl}$ and thrombolysis was associated with larger infarct size and poorer LVEF and LVEDVI at 6 months. A recently published subanalysis of the large randomized CIRCUS trial [9] showed no unfavorable effects of reSTE on LV contractility and remodeling at 1 -year follow-up. Patients with and without the reSTE primary endpoint composed of all-cause mortality and heart failure were found with similar proportion (19.2 vs. $19.8 \%, p=0.887$ ) at 1 year. It should be emphasized that only patients with a large anterior wall infarction were included in this study, which may mask the effects associated with reSTE. Our findings suggest that the incidence of reSTE following $\mathrm{PCI}$ in a patent IRA produces the risk of LVEF deterioration on average by $4.4 \%$ and the risk of LVEDVI or LVESVI increase by 7 or $8.5 \mathrm{ml} / \mathrm{m}^{2}$, respectively.

In the context of high prevalence of impaired tissue-level microvascular perfusion in patients with reSTE following $\mathrm{PCl}$ in a spontaneously reperfused IRA and its unfavorable long-term LV consequences, implementation of appropriate preventive and therapeutic strategies seems to be a key goal. As was documented in the DEFER-STEMI study [24], deferred PCI in selected STEMI patients reduced no-reflow, distal embolization and other thrombotic complications as compared with immediate stenting. However, other studies provided considerably less optimistic conclusions. In DANAMI 3-DEFER [25], deferred $\mathrm{PCl}$ did not reduce the occurrence of death, 
heart failure, $\mathrm{MI}$ or subsequent revascularization as compared with conventional $\mathrm{PCl}$. Moreover, routine deferred stenting was associated with a higher frequency of target vessel revascularization. A recent meta-analysis summarizing prior randomized trials showed that the deferred-stenting strategy did not reduce the occurrence of no-reflow, death, $\mathrm{MI}$ or repeated revascularization despite improved LVEF in long-term observation [26]. Based on these findings, routine deferred stenting is not recommended in the current European Society of Cardiology (ESC) guidelines [27]. Another intensively investigated strategy is thrombus aspiration. The two recent randomized trials TASTE [28] and TOTAL [29] showed no clinical benefit of routine thrombus aspiration in STEMI patients, suggesting possible increased risk of stroke. A meta-analysis of the trials TAPAS [30], TASTE and TOTAL finally confirmed that routine thrombus aspiration in STEMI patients did not improve clinical outcomes [31]. This meta-analysis, however, highlighted the group with high thrombus burden in which use of aspiration thrombectomy was associated with lower cardiovascular mortality $(\mathrm{HR}=0.80,95 \% \mathrm{Cl}: 0.65-0.98)$ but also with increased risk of stroke or transient ischemic attack (OR $=1.56,95 \% \mathrm{Cl}: 1.02-2.42$ ). Based on these data, routine thrombus aspiration is also not recommended in current ESC guidelines but in cases of large residual thrombus burden, after opening of the IRA, thrombus aspiration may be considered [27]. The current guidelines of ESC, however, permit the application of IIb/llla inhibitors as bailout therapy in the case of large thrombus, slow- or no-reflow, and other thrombotic complications [27]. Furthermore, a recently published study demonstrated the beneficial effect of early intracoronary administration of nicorandil on microcirculation damage [32]. Other strategies aimed at reduction of reperfusion injury, including cyclosporine, which activates mitochondrial potassium channels, failed to improve clinical outcomes and prevent LV remodeling [33], despite previous experimental studies indicating its beneficial effects on infarct size and microvascular obstruction [34].

Our study has several limitations. First, the sample size and the number of clinical adverse events are not large enough to draw clinical conclusions. Second, left ventricular remodeling was assessed by echocardiography, although cardiac magnetic resonance is a more accurate and objective method. Third, all participants were meticulously studied with serial ECGs only in the periprocedural period. Subsequent ECGs, including 6090 min after $\mathrm{PCl}$, were not prospectively recorded. Fourth, platelet reactivity [35], fibrin clot properties [36] and intracoronary thrombi [37] were not analyzed. However, these laboratory tests were beyond the main scope of this study.

\section{Conclusions}

ReSTE following $\mathrm{PCl}$ in patients with spontaneously recanalized IRA is associated with a lack of improvement of LV contractility and subsequent LV remodeling and therefore abolishes the beneficial effects of spontaneous reperfusion. Further studies on therapies to prevent reSTE following primary $\mathrm{PCI}$ are necessary.

\section{Acknowledgments}

This work was supported by a grant of the Jagiellonian University Medical College to J.Z. (N41/DBS/000006).

\section{Conflict of interest}

The authors declare no conflict of interest.

\section{References}

1. Fefer P, Beigel R, Atar S, et al. Outcomes of patients presenting with clinical indices of spontaneous reperfusion in ST-elevation acute coronary syndrome undergoing deferred angiography. J Am Heart Assoc 2017; 6: e004552.

2. Rakowski T, Dudek D, van't Hof A, et al. Impact of acute infarct-related artery patency before percutaneous coronary intervention on 30-day outcomes in patients with ST-segment elevation myocardial infarction treated with primary percutaneous coronary intervention in the EUROMAX trial. Eur Heart J Acute Cardiovasc Care 2018; 7: 514-21.

3. Rakowski T, Dudek D, Dziewierz A, et al. Impact of infarct-related artery patency before primary $\mathrm{PCl}$ on outcome in patients with ST-segment elevation myocardial infarction: the HORIZONS-AMI trial. Eurointervention 2013; 8: 1307-14.

4. Dudek D, Rakowski T, El Massri N, et al. Patency of infarct related artery after pharmacological reperfusion during transfer to primary percutaneous coronary intervention influences left ventricular function and one-year clinical outcome. Int I Cardiol 2008; 124: 326-31.

5. Roffi M, Patrono C, Collet JP, et al. 2015 ESC Guidelines for the management of acute coronary syndromes in patients presenting without persistent ST-segment elevation: Task Force for the Management of Acute Coronary Syndromes in Patients Presenting without Persistent ST-Segment Elevation of the European Society of Cardiology (ESC). Eur Heart J 2016; 37: 267-315.

6. Lemkes JS, Janssens GN, van der Hoeven NW, et al. Timing of revascularization in patients with transient ST-segment elevation myocardial infarction: a randomized clinical trial. Eur Heart J 2019; 40: 283-91.

7. Thygesen $\mathrm{K}$, Alpert JS, Jaffe AS, et al. Fourth universal definition of myocardial infarction (2018). Eur Heart J 2019; 40: 237-69.

8. Park DW, Kim YH, Yun SC, et al. Frequency, causes, predictors, and clinical significance of peri-procedural myocardial infarction following percutaneous coronary intervention. Eur Heart J 2013; 34: 1662-9.

9. Cuenin L, Lamoureux S, Schaaf M, et al. Incidence and significance of spontaneous ST segment re-elevation after reperfused anterior acute myocardial infarction - relationship with infarct size, adverse remodeling, and events at 1 year. Circ J 2018; 82: 1379-86.

10. Matano S, Iwasaki K, Kusachi S, et al. ST-segment re-elevation unrelated to left ventricular ejection fraction or volume after an- 
terior wall acute myocardial infarction treated with successful reperfusion. J Electrocardiol 2002; 35: 87-93.

11. Okuda J, Kosuge M, Ebina T, et al. Clinical implications of serial changes in ST-segment elevation after reperfusion in patients with anterior acute myocardial infarction. Circ J 2008; 72: 409-14.

12. Weaver JC, Ramsay DD, Rees D, et al. Dynamic changes in ST segment resolution after myocardial infarction and the association with microvascular injury on cardiac magnetic resonance imaging. Heart Lung Circ 2011; 20: 111-8.

13. Shimizu M, Ishikawa K, Kanamasa K, et al. ST-segment re-elevation and left ventricular expansion soon after acute anterior myocardial infarction. Jpn Circ J 1992; 56: 235-42.

14. The TIMI Study Group. The Thrombolysis in Myocardial Infarction (TIMI) trial. Phase I findings. N Engl I Med 1985; 312: 932-6.

15. Gibson CM, Cannon CP, Murphy SA, et al. Relationship of TIMI myocardial perfusion grade to mortality after administration of thrombolytic drugs. Circulation 2000; 101: 125-30.

16. Gibson CM, de Lemos JA, Murphy SA, et al. Combination therapy with abciximab reduces angiographically evident thrombus in acute myocardial infarction: a TIMI 14 substudy. Circulation 2001; 103: 2550-4.

17. Lang R, Badano L, Mor-Avi V, et al. Recommendations for cardiac chamber quantification by echocardiography in adults: an update from the American Society of Echocardiography and the European Association of Cardiovascular Imaging. J Am Soc Echocardiogr 2015; 28: 1-39.

18. Grabka $M$, Kocierz-Woźnowska $M$, Wybraniec $M$, et al. Left ventricular reverse remodeling in patients with anterior wall ST-segment elevation acute myocardial infarction treated with primary percutaneous coronary intervention. Adv Interv Cardiol 2018; 14: 373-82.

19. Fokkema ML, Vlaar PJ, Svilaas T, et al. Incidence and clinical consequences of distal embolization on the coronary angiogram after percutaneous coronary intervention for ST-elevation myocardial infarction. Eur Heart J 2009; 30: 908-15.

20. Zalewski J, Bogaerts K, Desmet W, et al. Intraluminal thrombus in facilitated versus primary percutaneous coronary intervention: an angiographic substudy of the ASSENT-4 PCI (Assessment of the Safety and Efficacy of a New Treatment Strategy with Percutaneous Coronary Intervention) trial. J Am Coll Cardiol 2011; 57: 1867-73.

21. Zalewski J, Nycz K, Przewlocki T, et al. Evolution of myocardial perfusion during primary angioplasty in spontaneously reperfused infarct-related artery: impact on long-term clinical outcomes and left ventricular function recovery. Int J Cardiol 2011; 147: 25-31.

22. Zalewski J, Zmudka K, Musialek P, et al. Detection of microvascular injury by evaluating epicardial blood flow in early reperfusion following primary angioplasty. Int J Cardiol 2004; 96: 389-96.

23. Driesen RB, Zalewski J, Driessche NV, et al. Histological correlate of a cardiac magnetic resonance imaged microvascular obstruction in a porcine model of ischemia-reperfusion. Cardiovasc Pathol 2012; 21: 129-31.

24. Carrick D, Oldroyd KG, McEntegart M, et al. A randomized trial of deferred stenting versus immediate stenting to prevent no- or slow-reflow in acute ST-segment elevation myocardial infarction (DEFER-STEMI). J Am Coll Cardiol 2014; 63: 2088-98.

25. Kelbæk H, Høfsten DE, Køber L, et al. Deferred versus conventional stent implantation in patients with ST-segment elevation myocardial infarction (DANAMI 3-DEFER): an open-label, randomised controlled trial. Lancet 2016; 387: 2199-206.

26. Qiao J, Pan L, Zhang B, et al. Deferred versus immediate stenting in patients with ST-segment elevation myocardial infarction: a systematic review and meta-analysis. J Am Heart Assoc 2017; 6: e004838.

27. Ibanez B, James S, Agewall S, et al. 2017 ESC Guidelines for the management of acute myocardial infarction in patients presenting with ST-segment elevation: The Task Force for the management of acute myocardial infarction in patients presenting with ST-segment elevation of the European Society of Cardiology (ESC). Eur Heart J 2018; 39: 119-77.

28. Jolly SS, Cairns JA, Yusuf S, et al. Randomized trial of primary PCI with or without routine manual thrombectomy. N Engl J Med 2015; 372: 1389-98.

29. Vlaar PJ, Svilaas T, van der Horst IC, et al. Cardiac death and reinfarction after 1 year in the Thrombus Aspiration during Percutaneous coronary intervention in Acute myocardial infarction Study (TAPAS): a 1-year follow-up study. Lancet 2008; 371: 1915-20.

30. Lagerqvist B, Fröbert O, Olivecrona GK, et al. Outcomes 1 year after thrombus aspiration for myocardial infarction. N Engl J Med 2014; 371: 1111-20.

31. Jolly SS, James S, Džavík V, et al. Thrombus aspiration in ST-segment-elevation myocardial infarction: an individual patient meta-analysis: thrombectomy trialists collaboration. Circulation 2017; 135: 143-52.

32. Feng C, Han B, Liu Y, et al. Effect of nicorandil administration on myocardial microcirculation during primary percutaneous coronary intervention in patients with acute myocardial infarction. Adv Interv Cardiol 2018; 14: 26-31.

33. Cung TT, Morel O, Cayla G, et al. Cyclosporine before PCl in patients with acute myocardial infarction. N Engl J Med 2015; 373 : 1021-31.

34. Zalewski J, Claus P, Bogaert J, et al. Cyclosporine A reduces microvascular obstruction and preserves left ventricular function deterioration following myocardial ischemia and reperfusion. Basic Res Cardiol 2015; 110: 18.

35. Zalewski J, Durak M, Lech P, et al. Platelet activation and microvascular injury in patients with ST-segment elevation myocardial infarction. Kardiol Pol 2012; 70: 677-84.

36. Zalewski J, Bogaert J, Sadowski M, et al. Plasma fibrin clot phenotype independently affects intracoronary thrombus ultrastructure in patients with acute myocardial infarction. Thromb Haemost 2015; 113: 1258-69.

37. Zalewski J, Lewicki L, Krawczyk K, et al. Polyhedral erythrocytes in intracoronary thrombus and their association with reperfusion in myocardial infarction. Clin Res Cardiol 2019; 108: 950-62. 